\title{
DA LIBERDADE DE EXPRESSÃO À FORÇA INSTAURADORA DA PALAVRA ${ }^{1}$ FROM FREEDOM OF SPEECH TO THE INAUGURAL FORCE OF THE WORD
}

\author{
Luciana Pereira Queiroz Pimenta Ferreira* \\ Isaque Rafael Castella Gonçalves***
}

Pois bem, arriscarei primeiro, antes de propriamente começar, duas afirmações. Também elas hão-de parecer incompatíveis. Não apenas contraditórias em si mesmas, desta vez, mas contraditórias entre si. Assumem a forma de uma lei, de cada vez uma lei. (...) - Seja. Quais são, então, estas duas afirmações? Escuto-te. - Ei-las:

1. Não falamos nunca senão uma única língua. 2. Não falamos nunca uma única língua. DERRIDA, O Monolinguismo do Outro, p. 19.

\begin{abstract}
Resumo
Neste artigo, pretendemos apresentar uma das mais recentes controvérsias públicas, no Brasil, sobre a extensão da liberdade de expressão, engendrada com o chamado inquérito das fake news (INQ 4781), instaurado no âmbito do Supremo Tribunal Federal com vistas à investigação de ameaças e notícias falsas contra os ministros da corte e a própria instituição, a partir do debate estabelecido entre os professores juristas Clarissa Gross, Lenio Streck, Marcelo Cattoni e Marcelo Galuppo. O artigo é composto de duas partes. A primeira se dedica a apresentar e situar as distintas posições argumentativas sustentadas publicamente e a segunda oferece uma contribuição teórico-epistemológica com vistas à ampliação teórica dos horizontes desse debate, do ponto de vista de suas implicações. O objetivo do artigo é tensionar as fronteiras da argumentação apresentada e reconhecer a força instauradora da palavra, assumindo uma herança desconstrucionista implicada em uma ética da alteridade, a partir do pensamento de Jacques Derrida.
\end{abstract}

Artigo submetido em 14 de julho de 2020 e aprovado em 20 de setembro de 2020.

${ }^{1} \mathrm{O}$ presente artigo é produto das pesquisas desenvolvidas em torno da filosofia da desconstrução de Jacques Derrida, uma das ramificações dos estudos do Grupo de Pesquisa Direito e Literatura: Um olhar para as questões humanas e sociais a partir da Literatura (PUC/CNPq).

* Doutora em Direito, pela PUC Minas; Mestre em Filosofia Social e Política, pela UFMG; Professora do Curso de Direito da PUC Minas, Co-coordenadora do Grupo de Pesquisa Direito e Literatura: Um olhar para as questões humanas e sociais a partir da Literatura (PUC/CNPq); Pesquisadora do Grupo Mulheres em Letras (FALE-UFMG/CNPq) e Poeta. (Lattes: Luciana Pereira Queiroz Pimenta Ferreira: FERREIRA, Luciana e PIMENTA, Luciana). E-mail: pereirapimenta@ hotmail.com.

** Mestrando na linha de pesquisa "Constitucionalismo democrático" do Programa de Pós-Graduação em Direito da PUC Minas com bolsa de FAPEMIG; Bacharel em Direito, pela PUC Minas; Bacharel em Comunicação Social - Jornalismo, pela UFMG; Integrante do Grupo de Pesquisa Direito e Literatura: Um olhar para as questões humanas e sociais a partir da Literatura (PUC/CNPq); (Lattes: Isaque Rafael Castella Gonçalves: GONÇALVES, Isaque Rafael Castella). E-mail: isaquecastella@ hotmail.com. 
Palavras-chave: Liberdade de expressão. Argumentação. Palavra. Ética da alteridade. Jacques Derrida.

\begin{abstract}
In this article, we intend to present one of the most recent public controversies, in Brazil, about freedom of speech's extension, generated from the called fake news inquiry, established within the scope of the Supreme Federal Court with a view to investigating threats and fake news against the court ministers and the institution itself, based on the debate between law professors Clarissa Gross, Lenio Streck, Marcelo Cattoni and Marcelo Galuppo. The article consists of two parts. The first is dedicated to presenting and situating the different argumentative positions supported publicly and the second offers a theoretical-epistemological contribution with a view to the expansion of this debate's horizons, from the point of view of its implications. The article's objective is to tension the frontiers of the presented argumentation and to recognize the inaugural force of the word, assuming a deconstructionist heritage implied in an ethics of otherness, based on the Jacques Derrida's thought.
\end{abstract}

Keywords: Freedom of speech. Argumentation. Word. Ethics of otherness. Jacques Derrida.

\title{
INTRODUÇÃO
}

Discutir os limites à liberdade de expressão, enquanto direito fundamental, é um grande desafio, recorrentemente presente na arena jurisdicional. Um debate que se torna crucial quando se compreende, por um lado, que essa arena prática é um espaço de permanente refundação da abordagem do fenômeno jurídico, vale dizer, da produção científica do Direito e, por outro, que a liberdade de expressão não é um direito dentre outros, mas um pilar fundamental das democracias constitucionais.

A produção científica do Direito é um dos fazeres mais relevantes de uma universidade e de uma comunidade de juristas que atua nesse lugar e pr'além dele, mas nunca sem vínculo, formal ou não, com o espaço institucional de produção desse saber. Um saber que não é puramente teorético, nem puramente prático, antes um saber em que teoria e práxis se encontram mutuamente implicadas.

Reconhecer a implicação entre teoria e práxis no campo do Direito tem consequências diretas sobre uma certa compreensão, tanto de cunho hermenêutico, quanto ético, que inevitavelmente se deixa sentir na relação entre Direito e Política, na medida em que traz à tona uma discussão sobre as escolhas que fazemos, no plano do agir, bem como um debate 
sobre as consequências dessas escolhas, no mundo da vida, e nossas responsabilidades perante essas consequências, no plano histórico.

Uma das mais recentes controvérsias públicas, no Brasil, sobre a extensão da liberdade de expressão, foi engendrada com o chamado inquérito das fake news (INQ 4781), instaurado no âmbito do Supremo Tribunal Federal com vistas à investigação de ameaças e notícias falsas contra os ministros da corte e a própria instituição democrática. Este artigo pretende apresentar a controvérsia a partir do debate argumentativo envolvendo os professores juristas Clarissa Gross, Lenio Streck, Marcelo Cattoni e Marcelo Galuppo

O início do debate remonta à entrevista concedida pela professora Clarissa Gross ao jornal Folha de São Paulo. Em seguida, discordando da posição sustentada por Gross em torno da liberdade de expressão, os professores Lenio Streck e Marcelo Cattoni publicaram uma resposta na Revista Consultor Jurídico. Na sequência, o professor Marcelo Galuppo entrou em cena, em defesa de Gross, em artigo de opinião na mesma revista eletrônica. Por último, Streck e Cattoni novamente se manifestaram, dessa vez respondendo às críticas de Galuppo.

Este artigo é composto de duas partes. A primeira dedicada a apresentar e situar as distintas posições no seio da comunidade de juristas, a partir dos argumentos da professora Clarissa Gross e dos professores Lenio Streck, Marcelo Cattoni e Marcelo Galuppo. Depois de expor o debate, numa segunda parte, pretende oferecer uma contribuição teóricoepistemológica com vistas à ampliação teórica dos horizontes desse debate, do ponto de vista de suas implicações éticas.

\section{O DEBATE SOBRE A LIBERDADE DE EXPRESSÃO NA CENA JURÍDICA CONTEMPORÂNEA BRASILEIRA: HÁ LIMITES?}

Em entrevista para o jornal Folha de São Paulo, a professora Clarissa Gross foi questionada sobre o voto do ministro Alexandre de Moraes pela continuidade do inquérito das fake news, o qual defende a distinção entre críticas ácidas e ameaças, no âmbito de concretização do direito à liberdade de expressão. Somente as primeiras estariam protegidas como liberdade de expressão, em sua visão, ao passo que ameaças deveriam ser punidas pelo Direito. Para a entrevistada, todavia, uma ameaça, para ser punida pelo direito, "tem que ser feita por alguém num contexto que traga indícios que a pessoa de fato terá condições de tomar medidas para impedir o exercício da magistratura pelos ministros do STF” (GROSS, 2020). 
Para a professora Gross, como consta da sequência da entrevista, mesmo aqueles que conclamam o fechamento do STF devem ser protegidos pela liberdade de expressão, vez que, embora não tenham o direito de implementar tal ideia, as pessoas teriam o direito de defendêla. E, perguntada se essa defesa não seria contrária às bases do Estado democrático de Direito, ela afirma que não e arremata explicando que "a proteção da liberdade de advogar por essas ideias faz parte da liberdade de expressão em um Estado democrático de Direito" (GROSS, 2020).

Gross acrescenta alguns exemplos para ilustrar seu ponto de vista, a saber, a circulação do Manifesto Comunista, de Karl Marx e Friedrich Engels, ou de escritos anarquistas, que abarcariam teses dissonantes às do Estado democrático de Direito. Seus defensores devem ser protegidos pela liberdade de expressão. Ela lembra que "essas ideias circulam no debate público, e nós as protegemos. Não nos passaria pela cabeça banir, por exemplo, a edição e a publicação de novas edições do Manifesto Comunista" (GROSS, 2020).

Ao mesmo tempo que corroboram a linha argumentativa de Gross, tais exemplos, como exercício comparativo, também podem ser mobilizados na compreensão da crítica central apontada por Lenio Streck e Marcelo Cattoni. Ocorre que os constitucionalistas em questão divergem do que consideram uma concepção meramente abstrata, a-histórica, da liberdade de expressão. Para eles, "liberdade de expressão sem crítica aos contextos, sem considerar os atingidos, como se ela pairasse acima e além da história, parece-nos um equívoco. Equívoco histórico, político e jurídico" (STRECK; CATTONI DE OLIVEIRA, 2020b).

Streck e Cattoni parecem buscar, na resposta à entrevista da professora Gross, o enfrentamento de uma visão excessivamente liberal no tratamento da questão da liberdade de expressão, a qual seria incompatível com toda a experiência histórica do século XX. Contra a tendência de um liberalismo autoritário, assumem a crítica a "certas interpretações por demais frouxas da liberdade de expressão (liberdade de expressão contra a democracia? Contra direitos humanos? Contra grupos vulneráveis?)" (STRECK; CATTONI DE OLIVEIRA, 2020b).

Em que pese o sentido normativo da liberdade de expressão esteja em disputa na esfera pública, os professores explicam que "não se pode desconsiderar, sobre o pano de fundo de um longo processo de aprendizagem social com inúmeras experiências históricas de injustiças e de violências, o que, pelo menos, liberdade e igualdade não significam" (STRECK; CATTONI DE OLIVEIRA, 2020b). Só uma perspectiva histórica permitiria 
compreender determinados grupos minoritários, não necessariamente em termos numéricos, como alvos preferenciais de discursos violentos. É nesse sentido que Streck e Cattoni destacam que

\begin{abstract}
o aplicador do direito deve buscar problematizar a mensagem que sua decisão possa estar encaminhando tanto aos que proferem os discursos de ódio, quanto aos seus destinatários, sob pena de, ainda que nas entrelinhas, edificarmos simbólicas indiferenças perante grupos que, historicamente, têm sido os mais atingidos por tais discursos odiosos (STRECK; CATTONI DE OLIVEIRA, 2020b).
\end{abstract}

Mister salientar que Streck e Cattoni afirmam não estarem negligenciando a importância da liberdade de expressão como aspecto constitutivo essencial ao Estado democrático de Direito e as legítimas preocupações que compartilham com Gross, face ao risco de promoção de censuras. Quanto a estas, diferenciam a censura prévia ao discurso, que seria ilegítima, da possibilidade de responsabilização a posteriori pelo que se expressa, em se caracterizando abuso no gozo da liberdade de expressão (STRECK; CATTONI DE OLIVEIRA, 2020b).

Marcelo Galuppo parece concordar com a impossibilidade de se limitar previamente um discurso pelo seu conteúdo, embora afirme expressamente que a argumentação de Streck e Cattoni vai no sentido contrário. Em sua visão, “o cerne da questão parece ser que Gross e eu acreditamos que não se pode limitar o discurso previamente por causa de seu conteúdo, enquanto Streck e Cattoni parecem acreditar que o discurso sempre pode ser limitado" (GALUPPO, 2020).

O que se percebe, quanto a esse ponto, é uma convergência entre os debatedores, o que levou o professor Gustavo Ferreira Santos a afirmar: "entre os quatro professores, há mais concordâncias do que discordâncias. Nenhum defende censurar previamente discursos" (SANTOS, 2020). Tal conclusão está amparada na afirmação posterior de Streck e Cattoni, preocupados em esclarecer que

\footnotetext{
não estamos dizendo que certos discursos devam ser previamente censurados, por si sós, mediante um suposto privilégio de acesso a uma verdade ou correção transcendental. O que estamos falando é de responsabilidade pelo que foi expressado. Em outras palavras, devemos levar a história do Direito a sério (STRECK; CATTONI DE OLIVEIRA, 2020a).
}

O texto de Galuppo, ao que parece, visa defender a professora Gross do que seria uma incompreensão de sua posição no debate sobre a liberdade de expressão, vez que, diferentemente de Streck e Cattoni, que puderam elaborar seu artigo de opinião de forma a 
organizar uma linha argumentativa com tempo e espaço, Gross não teria tido a mesma oportunidade. A entrevista caracterizaria uma conversa sem conhecimento prévio das perguntas e sem o devido tempo para reflexão sobre as respostas (GALUPPO, 2020).

Enquanto pesquisador da liberdade de expressão, Galuppo considera ser possível compreender claramente o que Clarissa Gross queria dizer com suas palavras, por mais que concorde em não terem sido as mais apropriadas. Ele associa a posição de Gross, e a sua própria, à concepção de liberdade de expressão proveniente de uma vasta tradição de autores e de casos paradigmáticos no âmbito da jurisdição constitucional estadunidense. Dessa forma, quando a professora

\begin{abstract}
se referiu à capacidade de o discurso induzir à ação como único limite, ela estava se referindo a uma vasta tradição que passa por John Locke, John Stuart Mill, Oliver Holmes, Jr., Louis Brandeis, Billing Learned Hand, Alexander Meiklejohn, C. Edwin Baker, Stanley Fish e Ronald Dworkin, mas também pelos leading cases norte-americanos Brandenburg v. Ohio, National Socialist Party of America v. Village of Skokie, R. A. V. v. City of St. Paul e, sobretudo, New York Times, Co. v. Sullivan (GALUPPO, 2020).
\end{abstract}

Pelo fato de os argumentos da professora Clarissa Gross estarem respaldados no desenvolvimento do pensamento constitucional, ao longo dos últimos séculos e décadas, Galuppo discorda de Streck e Cattoni quando estes sugerem que Gross estaria desprezando ou desconsiderando uma perspectiva histórica da liberdade de expressão. Ao contrário, a professora, mesmo sem a oportunidade de enunciá-la em sua entrevista, teria deixado, nas entrelinhas de suas respostas, toda uma construção teórica e jurisprudencial (GALUPPO, 2020).

De acordo com a tradição resgatada, Galuppo tece sua consideração, indo ao encontro da ideia sustentada por Gross, sobre o tão debatido inquérito das fake news, no sentido de que "a incitação ao crime contra os familiares dos ministros deve ser avaliada em termos de sua capacidade de induzir performativamente à ação (o que talvez seja o caso aqui)" (GALUPPO, 2020).

Em uma resposta final, ao menos provisoriamente, Lenio Streck e Marcelo Cattoni colocam algumas objeções aos argumentos defendidos por Marcelo Galuppo, sobretudo no que concerne à história constitucional estadunidense. Para os professores, não há um consenso em torno da interpretação da Primeira Emenda, sendo que

os pensadores citados por Galuppo refletiriam apenas o establishment, não aquelas e aqueles que com ele divergem. Mas, como afirma o próprio Dworkin, em Freedom's 
Law, o que era "heterodoxia" em Holmes, no início do século XX, passa a ser "ortodoxia" em Brandenburg, nos anos 60. Não há um só lado nessas controvérsias! É possível elencar várias e vários autores divergentes, inclusive entre si, como Richard Delgado, Mary Matsuda, Charles Lawrence, Catharine MacKinnon e mesmo Jeremy Waldron. Além disso, esses autores citados por Galuppo sequer constituiriam uma escola ou linha de pensamento única, porque suas posições se constituíram a partir de controvérsias concretas, não de teorias abstratas. Assim, elencar o que eles disseram sobre liberdade de expressão, fora das controvérsias e sem levar a sério a historicidade dos debates, é sempre correr o risco de reducionismo (STRECK; CATTONI DE OLIVEIRA, 2020a).

Novamente, Streck e Cattoni criticam que a caracterização da liberdade de expressão possa se dar de maneira abstrata, desconectada de uma historicidade. E, para ilustrar, Streck e Cattoni lançam mão de um exemplo ao pontuarem que "sem levar a história a sério, uma cruz pegando fogo no quintal de uma família afroamericana seria apenas uma madeira em chamas - e não é, de modo algum, apenas isso" (STRECK; CATTONI DE OLIVEIRA, 2020a). Ou seja, o que abstratamente poderia ser tratado como liberdade de expressão precisa ser contextualizado, compreendido à luz de sentidos históricos. Trata-se de uma leitura hermenêutica da questão.

Streck e Cattoni apontam a necessidade de consideração das assimetrias existentes entre falantes e ouvintes diversos. E questionam: “como um afromericano pode 'dialogar' com uma placa que diz 'whites only’? Ele pode 'escolher'? Essa placa só relata (...) ou já levanta a pretensão de como o 'mundo' deve ser?” (STRECK; CATTONI DE OLIVEIRA, 2020a). Eles abordam tais argumentos diante da colocação de Galuppo de que a democracia não pode implicar em cidadãos tutelados sobre o que podem ouvir, mas, ao contrário, apenas em cidadãos capazes de escolher entre argumentos difundidos livremente (GALUPPO, 2020).

Parece explícita, nesse ponto, uma controvérsia entre uma posição mais liberal e outra que critica o que chama de "excesso autoritário de liberalismo complacente com a violência". Para Streck e Cattoni, liberdade de expressão não pode servir como pretexto atrás do qual pretendem se esconder aqueles que promovem segregação, silenciamento e negacionismo histórico (STRECK; CATTONI DE OLIVEIRA, 2020a).

$\mathrm{Na}$ sequência, denunciam a posição hegemônica sobre liberdade de expressão no contexto dos Estados Unidos da América, que estaria na contramão de outras democracias ocidentais, como a alemã. Nas palavras dos constitucionalistas, "essa visão ultraliberal de liberdade de expressão é a que leva, inclusive, os Estados Unidos a irem contra uma série de iniciativas internacionais, colocando-se na companhia de reconhecidas ditaduras" (STRECK; CATTONI DE OLIVEIRA, 2020a). 
Streck e Cattoni, críticos da concepção liberal, contrapõem o entendimento majoritário da matéria na Suprema Corte estadunidense à jurisprudência consolidada no Supremo Tribunal Federal e na Corte Constitucional Federal da Alemanha. Eles analisam que nesses contextos "somos responsáveis pelo exercício da liberdade de expressão, sobre o pano de fundo de todas as disputas travadas pelo constitucionalismo que, inclusive, reconhece, como aprendizado histórico, o risco de pretensões abusivas e de suas consequências concretas" (STRECK; CATTONI DE OLIVEIRA, 2020a).

Ainda sobre as decisões da Suprema Corte dos Estados Unidos, apontam que a visão liberal da liberdade de expressão não é capaz de enxergar os constante e permanentemente atingidos pelos discursos de ódio, quais sejam, os grupos minoritários em termos políticos, em situação de vulnerabilidade com relação ao conjunto da sociedade estadunidense. Segundo Streck e Cattoni (2020a), "literalmente, eles não interessam (...) para a Suprema Corte estadunidense, pois a liberdade de expressão é traduzida 'em abstrato"”.

\section{3 "NÃO FALAMOS NUNCA SENÃO UMA ÚNICA LÍNGUA. NÃO FALAMOS NUNCA UMA ÚNICA LÍNGUA": DO DIÁLOGO À FORÇA INSTAURADORA DA PALAVRA}

O debate ora apresentado é, notadamente, de cunho argumentativo. Faz parte de uma certa visão hegemônica da vida social uma ideia (e o termo aqui é propositadamente ideia, no sentido kantiano de uma ideia da razão) de que a razão (do sujeito) se encaminhou para um horizonte de diálogo, consubstanciando, em termos habermasianos, um modelo de racionalidade discursivo, a partir do qual nossas ações seriam sempre orientadas e avaliadas pelo melhor argumento, a partir do qual se pode obter um consenso racional.

Reconhecendo uma tal herança e sobre ela atuando, partirmos aqui de uma questão preliminar, qual seja, aquela que gira em torno dos supostos limites do debate, adotando, para tanto, um ponto de vista desconstrucionista ${ }^{2}$. Em Desconstrução e Pragmatismo, Derrida lembra que a questão mais frequentemente levantada sobre o tema da desconstrução é precisamente a da argumentação: "Sou censurado - desconstrucionistas são censurados - por não gostar de argumentação, etc. etc.” (DERRIDA, 2016, p.120). Isso obviamente é uma difamação, pontua Derrida, porque o que a desconstrução faz é aumentar os limites da

\footnotetext{
${ }^{2}$ A desconstrução deve ser entendida aqui como um movimento de atuação sobre a argumentação, o qual se dá internamente, e não fora dela, como uma transgressão situada no tensionamento entre o dito e o não-dito. Como explica Rafael Haddock-Lobo, um dos principais estudiosos brasileiros de Derrida, "este tipo de transgressão implica somente o fato de o limite ou as margens do pensamento estarem sempre em movimento" (HADDOCKLOBO, 2007, p. 70).
} 
argumentação, o que frequentemente é desconsiderado ou rechaçado por propostas que se querem governadas por determinadas formas proposicionais do discurso.

E o que me interessa, obviamente, são outros protocolos, outras situações argumentativas, em que não se renuncia à argumentação simplesmente porque se recusa a discutir sob certas condições. Como uma das consequências, penso que a questão da argumentação seja central aqui, discussão é central aqui. Penso que as acusações feitas frequentemente à desconstrução são provenientes do fato de que o aumento de seus limites de argumentação não é considerado. (DERRIDA, 2016, p.120/121).

Queremos, com esse ponto de partida, trazer à reflexão a necessidade de considerarmos o debate argumentativo em questão à luz, inclusive, da questão que pergunta se podemos resolver todas as questões sobre nossas diferenças, em sociedades democráticas, a partir de um ponto de vista sempre dialogal e argumentativo, pressupondo que não haja violência no dizer, bem como sublimando que, por trás do jogo argumentativo estejam, em verdade, nossas escolhas ou adesões irracionais.

Por mais paradoxal que possa parecer - sob a perspectiva que sustenta que o diálogo é sempre o oposto da violência - uma visão como esta pode ser, ela mesma, a primeira a ensejar violência. Em outras palavras, talvez devamos não desconsiderar que há uma violência implícita no diálogo, na medida em que cada um queira impor a sua língua ou, em outros termos, na medida em que as condições para ouvir o Outro se coloquem a partir da exigência que o Outro fale a "minha" língua. A questão aparece em $O$ monolinguismo do Outro: "A tua frase não tem sentido, não tem o sentido comum, podes vê-la desaparecer por si mesma. Como é que se pode ter uma língua que não seja sua?” (DERRIDA, 1996, p. 15).

Em outros termos, como lembra o filósofo uspiano Vladimir Safatle, para dialogar, seria preciso pressupor uma gramática comum o que, todavia, não ocorre, estando exatamente aí a formulação de uma questão ética:

no entanto, talvez o problema esteja exatamente nesse ponto. Pois e se boa parte de nossos conflitos visassem exatamente mostrar que não há uma gramática comum no interior da vida social? Se eles nos mostrassem que, quando nos digladiamos a respeito do que significa "liberdade", "justiça", não temos uma gramática comum na qual nos apoiarmos, pois estamos ligados, pois somos legatários de experiências históricas muito distintas? (SAFATLE, 2017, p. 128)

Um dos pontos de vista para pensar tanto o diálogo quanto a questão da liberdade de expressão é, pois, sem dúvida, o da violência que é, aliás, o núcleo temático do inquérito das fake news (INQ 4781), instaurado no âmbito do Supremo Tribunal Federal, na medida em que tanto a ameaça quanto a falsidade das notícias são modalidades de violência. Tudo se passa, 
ali, no sentido de tomada de posições sobre quais violências o direito deveria punir, na hipótese.

Num diálogo de Derrida com a psicanalista Elizabeth Roudinesco, o tema da violência ganha contornos que muito nos interessam trazer para o presente debate. Embora estejam a discutir um outro tema, a saber, a violência contra os animais, onde o que está em pauta é a discussão da proibição de práticas violentas contra os animais (a violência científica, industrial e técnica), emerge ali uma questão acerca dos limites da proibição. Para Roudinesco, não se deve proibir todas as práticas violentas, sob o argumento de que uma sociedade higienista acabaria por implicar em uma sociedade recalcada.

\begin{abstract}
Sempre temi o engajamento no caminho da construção de uma sociedade higienista, sem paixões, sem conflitos, sem injúrias, sem violências verbais, sem risco de morte, sem crueldade. $\mathrm{O}$ que se pretende erradicar de um lado sempre carrega consigo o risco de ressurgir ali onde não se espera (ROUDINESCO, In: DERRIDA, 2004, p. 95).
\end{abstract}

Derrida, todavia, em que pese compreender e, como ele mesmo diz, ser capaz de partilhar o temor da psicanalista, constrói uma importante ilocução, em face do argumento apresentando por Roudinesco. Vejamos:

Com esta lógica, sob pretexto de que a proibição das violências pode levar ao surgimento de novas violências mais graves, por um efeito perverso, arrisca-se permitir todas as violências e baixar os braços. Eu poderia dar muitos exemplos que a preocupariam. Devemos nos abster de condenar ou denunciar as violências racistas, anti-semitas, xenófobas sob pretexto de que, "recalcadas" aqui ou ali, arriscam-se a ressurgir com mais força em outro lugar?” (DERRIDA, 2004, p. 95)

Trazendo o debate entre Roudinesco e Derrida para nossa reflexão, percebe-se claramente que o argumento de Roudinesco se ajusta a uma visão ultraliberal de sociedade, ao passo que a objeção de Derrida levanta uma questão tanto jurídica quanto ética acerca do que permitimos, com e em nome do Direito. Uma questão que se estende, também, à formulação do problema que ora levantamos, qual seja, o de que tanto a liberdade de expressão quanto o próprio debate argumentativo em torno dela não escapam de violências éticas cometidas com e sobre o Outro.

Na mesma linha de Derrida, Safatle recoloca a questão. Lembra que nossas sociedades são essencialmente antagônicas e que, para muitos, essa seria exatamente a necessidade de uma sociedade que respeitasse todas as diferenças. Mas, pergunta o filósofo: 
o que fazer quando temos aqueles que defendem a tortura, que exaltam as ditaduras militares ou que naturalizam a espoliação social das mulheres? Há que se respeitar essa "diferença"? Mas é realmente possível acreditar que podemos resolver tais diferenças através do diálogo? (SAFATLE, 2017, p. 133)

A questão é, sem dúvida, paradoxal. Mas ela porta um chamado a refletirmos acerca dos usos que temos feito da linguagem, nas formas constitutivas de ser e estar no mundo.

\begin{abstract}
A palavra que circula na experiência estética do poema, na experiência analítica da clínica e mesmo nas conversões de toda ordem não argumenta nem comunica. Ela instaura, ela mobiliza novos afetos e desativa os antigos, ela reconstrói identificações, em suma, ela persuade com uma persuasão que não se resume à explicação de argumentos, e isso vale também para os verdadeiros embates políticos. O que nos falta não é o diálogo, mas encontrar a palavra nessa sua força instauradora. (SAFATLE, 2017, p. 133)
\end{abstract}

Em outras palavras, atentos à especificidade da questão que nos colocou em reflexão: por que não pensar o debate sobre liberdade de expressão não como um debate de razões que visam ao convencimento ou consenso racional, mas como um debate em torno das escolhas ou adesões que fazemos, das consequências éticas que delas decorrem para o mundo que elas instauram? Por que não trazer para o debate quais são os afetos que ressoam desta discussão e daqueles que, talvez, devamos reconhecer como heranças que não podem ser desprezadas na refundação de outro mundo? Qual mundo queremos? Como minorar o mal estar da civilização? Qual herança escolhemos, diante dos testemunhos que damos, ao longo da história? Qual a nossa responsabilidade, pelo mundo em devir?

\title{
CONSIDERAÇÕES FINAIS
}

Motivados, inicialmente, pelo recente debate envolvendo célebres juristas brasileiros em torno da liberdade de expressão e seus limites ou ausência destes, procuramos destacar os principais argumentos levantados por Clarissa Gross e Marcelo Galuppo, de um lado, e por Lenio Streck e Marcelo Cattoni, de outro. Desse primeiro movimento, foi possível concluir que, embora concordem em muitos pontos, os professores se filiam a matrizes diferentes na concepção da liberdade de expressão: os dois primeiros acreditando na maior pertinência dos argumentos liberais e os dois últimos defendendo que quem tem razão são os críticos menos concessivos ao que chamam de liberalismo autoritário.

Pr'além de colocar um ponto final no debate, nosso empreendimento teórico buscou atuar e estabelecer, ainda que brevemente, um tensionamento das fronteiras da argumentação apresentada, assumindo como nossa uma herança desconstrucionista. O que fizemos, 
efetivamente, foi deslocar o debate da polaridade das matrizes teóricas das razões sustentadas para a indagação sobre as consequências éticas implicadas em nossas tomadas de posição.

Convictos de que não há neutralidade, questionando a instrumentalidade da linguagem, reconhecendo a violência do dizer e assumindo que posicionamentos partem de escolhas ou adesões irracionais que inauguram mundos e formas de vida possíveis, ou seja, de que há uma força instauradora da palavra, uma força que instaura e refunda, permanentemente, o mundo e a vida, procuramos, no rastro derridiano, trazer à tona um chamado a discutirmos liberdade de expressão sob um ponto de vista ético, ou seja, sob o prisma da responsabilidade o que, a dizer com Derrida, implica sempre em um compromisso com a alteridade, em todas os momentos que se tenha que decidir, singularmente. Um debate que já começou, mas nos lança sempre mais e além, na força instauradora da palavra. Um debate por vir, no sentido de uma abertura própria de todas as democracias.

\section{REFERÊNCIAS}

DERRIDA, Jacques. De que amanhã: diálogo Jacques Derrida; Elisabeth Roudinesco. Tradução de André Telles. Rio de Janeiro: Jorge Zahar Ed., 2004.

DERRIDA, Jacques. O Monolinguismo do Outro Ou a prótese de origem. Tradução Fernanda Bernardo. Porto: Campos das Letras, 2001.

DERRIDA, Jacques. Observações sobre desconstrução e pragmatismo. In: Desconstrução e Pragmatismo. Simon Critchley [et al] Organização Chantal Mouffe; Trad. Victor Dias Maia. Rio de Janeiro: Mauad X, 2016.

GALUPPO, Marcelo Campos. A democracia no Brasil corre risco. Consultor Jurídico, 24 jun. 2020. Opinião. Disponível em: https://www.conjur.com.br/2020-jun-24/marcelogaluppo-democracia-brasil-corre-risco. Acesso em: 13 jul. 2020.

GROSS, Clarissa. Inquérito das fake news no STF abre precedente perigoso para liberdade de expressão, diz pesquisadora. Entrevista cedida a Renata Galf. Folha de São Paulo, São Paulo, 20 jun. 2020. Disponível em: https://www1.folha.uol.com.br/poder/2020/06/inquerito-dasfake-news-no-stf-abre-precedente-perigoso-para-liberdade-de-expressao-dizpesquisadora.shtml. Acesso em: 13 jul. 2020.

HADDOCK-LOBO, Rafael. Considerações sobre "posições" de Derrida. O que nos faz pensar, n. 21, mai. 2007.

SAFATLE. Vladimir. É racional parar de argumentar. In: DUNKER, Christian et al. Ética e pós-verdade. Porto Alegre: Dublinense, 2017. 
SANTOS, Gustavo Ferreira. Fake news e democracia: entre o discurso do cidadão e a ação das máfias digitais. Consultor Jurídico, 26 jun. 2020. Opinião. Disponível em: https://www.conjur.com.br/2020-jun-26/gustavo-santos-fake-news-democracia. Acesso em: 14 jul. 2020.

STRECK, Lenio Luiz; CATTONI DE OLIVEIRA, Marcelo Andrade. Liberdade de expressão: levando a história do Direito a sério. Consultor Jurídico, 24 jun. 2020a. Opinião. Disponível em: https://www.conjur.com.br/2020-jun-24/streck-cattoni-levando-historiadireito-serio. Acesso em: 13 jul. 2020.

STRECK, Lenio Luiz; CATTONI DE OLIVEIRA, Marcelo Andrade. Pode-se, em nome da democracia, propor a sua extinção?. Consultor Jurídico, 22 jun. 2020b. Opinião. Disponível em: https://www.conjur.com.br/2020-jun-22/streck-cattoni-nome-democracia-proporextincao. Acesso em: 13 jul. 2020. 